\title{
Paul's Critique of CRITICAL THINKING AND EDUCATION
}

\author{
JOHN MCPECK University of Western Ontario
}

Usually, it is unwise for an author of a book even to attempt responding to a published critique of his/her book with a brief rebuttal. $\mathrm{He} / \mathrm{she}$ is always on the defense, and cannot, therefore, avoid appearing defensive. An essay in the New York Review of Books recently described all such attempted rebuttals as an "ABM": an Author's Big Mistake. (I can recall one rare, but notable, exception to this general caution. It is from the famous LeibnizClarke Correspondence, wherein Leibniz prudently responded to a lengthy and bitter critique by Clarke with but one statement: "I deny the major premise." Anything more is likely to become an ABM.)

In the present case, the editors of Informal Logic have kindly requested that I respond to Richard Paul's review of my Critical Thinking and Education (N.Y., St. Martin Press, 1981). And they have specifically asked that I not review this Review, but rather restrict myself to the "substantive philosophical differences between us". With this restriction in mind, therefore, I hope it becomes clear that my comments are not intended to rebut all of Paul's many charges. It is rather an attempt to uncover what $I$ think he has gotten wrong, and to discuss the "substantive philosophical differences between us". Putting the ABM aside, my intent is light, not heat.
I will treat each of Paul's more substantive points in their order of appearance.

Paul's opening comment about my books asserts that I made several "foundational mistakes", and that these have "serious flaws in their theoretical underpinnings". Little doubt the book might contain some of this. But as I examine Paul's critique, I find less evidence of "mistakes" and "serious flaws" than of misunderstanding of my position and perhaps genuine disagreement.

The first, and perhaps most pervasive, "mistake" that Paul finds is that I supposedly subscribe to "a rarefied form of logical atomism". It is never quite clear to me what, precisely, Paul means by "logical atomism". His meaning clearly differs from what most philosophers understand by that phrase, namely, the basic language elements in Wittgenstein's Tractatus. Nor is his meaning at all like Russell's meaning in The Philosophy of Logical Atomism (1918). Rather, Paul seems to be coining his own phrase which is apparently meant to refer to my view that not all knowledge and skills are cut from the same cloth. It is quite true that I defend the view that, for example, a critical mathematician possesses a kind of knowledge and skill that is different from a critical historian. And in general, different domains of 
knowledge have (more often than not) characteristically different patterns of reasoning and argument that are peculiar to themselves. This view, incidentally, is a well-trodden philosophical path which leads back to Aristotle's Posterior Analytics, or to Wittgenstein's Philosophical Investigations, particularly the notion of different "language games". Thus, while my particular statement of my position may or may not contain certain errors, it is, I think, gross overstatement to claim that the view contains "serious flaws in its theoretical underpinnings", or that it consists of serious "foundational mistakes". Aristotle, Wittgenstein, and I (if you'll forgive me) may all be wrong of course, but if so, it is not as obvious as Paul seems to think.

The major philosophical differences that divide Paul and me seem to reside in his basic charge that my position is "atomistic", or "technological/specialist" as he sometimes calls it. However, it seems to me that this charge is based upon both a misinterpretation of my view, and also an honest disagreement. At times, I confess, I'm not sure which is which, but let me try to explain these differences as succinctly as I can.

Paul marshals two separate and distinguishable arguments to support his charge (or characterization) of my position as being "atomistic", or "technological/specialist". The first argument concerns my rejection of generalized reasoning skills, and the second reflects his observation that most problems are in fact "multicategorical" and not domain-specific. Both of these arguments, however, are simply two different ways of rejecting my general view that critical thinking and rationality are primarily domainspecific and context-dependent (therefore, they do not represent "general reasoning skills," in Paul's desired sense). I will treat each of Paul's arguments in a moment, but I think there is a much larger problem that moderates our disagreement. This larger problem cannot be resolved here, but I think it important to recognize that it does exist and that it helps explain the nature of our disagreement.

As time goes on, it becomes increasingly clear to me that my differences with the Informal Logic Movement (ILM) generally, may have their roots in a fundamentally different conception of how logic and language are connected to thought. This fundamental difference amounts to nothing less than a Kuhn-type paradigm clash about the nature of these connections. Thus, we continue to talk past one another, like ships passing in the night, each failing to be persuaded by the other's arguments. This paradigm clash is between what I would call a Wittgensteinian view about the nature of logic, language and thought that stresses the semantic and pragmatic features of logic and the more typically North American view which stresses the formal, syntactical features of logic and reasoning. For Wittgenstein, logic inheres within language and speech acts themselves. For the logicist (or North American view) logic is an exogenous system of rules and principles into which language can be pluggedin as a variable. While Informal Logic is less mathematical, or less formal than formal logic, nonetheless it shares the same syntactic preoccupation with rules and principles of reasoning (of a weaker sort) that is so characteristic of formal logic proper. (Hence, the persistent talk about "theories of fallacy," "theories of reasoning," "theories of informal logic," etc., all of which seek generalizable canons of reasoning and argument in one form or other.) Wittgenstein, on the other hand, did not believe such canons of reasoning were forthcoming, because the locus of logic (not mathematical or formal, however) resides within the speech acts themselves. For Wittgenstein, you can no 
more separate the logic of a speech act from the act itself than you can separate all the thread from the cloth and still have the cloth. To the extent that this view might be true incidentally, it helps to explain the well known difficulties associated with trying to accurately portrait the true structure of real arguments with formal schemata - the more real the argument, the more difficult is the portrayal. Wittgenstein's view explains why this is so. I am not here trying to defend Wittgenstein, but merely trying to point out that when 'logic' and 'reasoning' are perceived from these fundamentally different points of view much confusion and misunderstanding is bound to ensue.

I first saw evidence of this basic clash at the First International Symposium on Informal Logic (University of Windsor, 1978) when Peter A. Minkus presented a paper from an avowedly Wittgensteinian point of view. (Its title was "Arguments That Aren't Arguments".) Despite the paper's unusual style, and at times confusing presentation, the amount of misunderstanding (and hostility) which it generated far surpassed any internal muddles it may have contained. The two paradigms had come face-to-face: neither understood the other. Further evidence of this clash can be found in Ralph Johnson's painstaking review of Stephen Toulmin's Introduction to Reasoning in this journal (March, 1981). In his bones, Toulmin is a Wittgensteinian, and he views logic from this perspective. But in Introduction to Reasoning he is trying to have it both ways by straddling the two paradigms: $\mathrm{He}$ is trying to fit a Wittgensteinian view of Logic, and logical relationships, into semi-formalistic mold. Needless to say, the fit is a very awkward one at best-as square pegs into round holes always are. Johnson, indeed, has done a fair and credible job showing the several ways in which Toulmin has failed in his objective. However, John- son's yardstick for measuring success or failure was a typically formalistic (e.g. North American) one. Toulmin's program simply does not square with formalistic desiderata, as Johnson correctly points out; but the latter Wittgenstein would have predicted as much.

The paradigm clash between Toulmin and Johnson is at its clearest in Johnson's discussion of Toulmin's key notion of a "warrant", which is intended to displace rules of inference Johnson writes:

Of all the elements in Toulmin's schema, the warrant is the one I had the greatest problem understanding. The intuitive idea seems clear enough, but (as I will try to show) Toulmin's rather breezy style of exposition creates some of the confusion. Then, too, this is the element that departs most radically from the traditional schema, thereby forcing one to look at the structure of arguments in a different light. That takes some getting used to. (p. 21)

Johnson also adds revealingly:

The problem is thorny enough to make one nanker for the rarified climes of formal logic-almost!

The "problem of understanding" which Johnson has with Toulmin's schema is, I submit, not simply a matter of incomplete comprehension that one might find between two informal logicians. It is, rather, a classic paradigm clash between two people who hold radically different views about the nature of the connection between logic, language, and thought. Such deep-rooted differences cannot be resolved by simply cleaning up a few terms like "warrant" or "ground", because these concepts have no equivalent meaning in the other paradigm. They are part of a different philosophical network.

I might say that I share Johnson's dissatisfaction with Toulmin's notion of "warrants"; it is woolly. However, 
I also share Toulmin's basic view about the nature of the connections between logic, language and thought (which is Wittgensteinian.) And this view, therefore, puts me in the other paradigm.

I think this difference helps to explain: (a) much of the deeper misunderstandings about my view, and (b) why my view seems to appear so a priori to some folks, including Richard Paul. It is interesting, incidentally, that in Great Britain, where the book was first published, my general position has been received with polite yawns, since it is there more or less commonplace. (This, of course, does not mean it is correct; but it does mean it is understood.) Enough, however, about this fundamental difference. It cannot be resolved here. But I think it important to recognize that it exists.

Back to Paul's two arguments as promised. The first, you will recall, has to do with my rejection of generalized reasoning skills, which Paul uses to support his general charge about my view being "atomistic" or "technological/specialist." With the possible exception of general intelligence (or I.Q.), I do deny generalized reasoning skills. Or, at least, we have not discovered any thus far (psychologists included). This rejection, however, does not entail nor suggest a "technological/specialist" view of human reasoning, as Paul implies. To say, as I do, that the various broad domains of human understanding (e.g. math, literature, science, morality) require different kinds of concepts, skills, and patterns of reasoning peculiar to themselves and not generalizable across domains, is not to insist that people must be "specialists," as such, in any particular area. It is, rather, to point out that the particular ingredients of rationality and critical thinking are less generic and more idiosyncratic than any single set of generalized reasoning skills can capture, namely, the so-called "critical thinking skills." On my view, to become rational one must come to understand the different logical, conceptual, and epistemic differences that obtain between the different kinds of questions and problems that there are (e.g. mathematical, scientific, philosophic, artistic, moral, etc.). When one clearly understands these logical differences, one comes to appreciate the different procedures (or methods) that might be appropriate for answering (and asking) questions in these domains. This, indeed, is precisely the kind of understanding which a liberal education attempts to provide. And it is a kind of understanding and preparation for critical thinking that I have repeatedly advocated in my book, and several other papers. Whatever else a liberal education is, it is not "technological/specialistic." Indeed, it is often criticized from some quarters (e.g. business) precisely because it does not provide enough specialized knowledge. It should not go unnoticed, by the way, that training in specific "reasoning skills" is far more specialized than anything that I could have advocated. Thus, the irony in the charge of "technological/specialist."

Paul argues that my rejection of generalized reasoning skills is a nonsequitur because, he argues, that it does not follow from the fact that thought requires a specific object " $X$ " (to be thought about) that there are no generalized reasoning skills. To show how "bizarre" he thinks this reasoning is, he attempts to draw analogies with general writing skills (or "composition",) and "general speaking skills":

Likewise most would think bizarre someone who argued that because speech requires something specific spoken about, it, therefore, is senseless to set up general courses in speech and incoherent to talk of general speaking skills.

But let us be very clear about something. I am not engaged in an analysis 
of 'writing,' nor of 'speaking': I am engaged in an analysis of 'thinking,' which is an entirely different concept. It might make sense to talk about "general writing skills," and perhaps "general speaking skills," but it does not follow from this (as Paul implies) that it makes similar sense to talk of "general thinking skills." There are people who can think, for example, but cannot write, just as there are people who can think but cannot speak. One would, therefore, expect things to be true of 'writing' and 'speaking' which might not be true of 'thinking.' Notice, for example, that we do sometimes say of someone that "He doesn't know what he is talking about," but it would be odd to assert that "He does not know what he is thinking about." 'Thinking' and 'speaking' are simply different concepts, and they refer to different kinds of tasks.

I would, moreover, point out that even in writing and in speaking the major portion of the task consists in having knowledge of what it is, specifically, that one is trying to write or speak about. As every teacher knows (particularly "composition" teachers), a student cannot write intelligently about something he does not understand. Clear understanding is a necessary condition for clear writing-infinite monkeys and typewriters notwithstanding. The same for speaking. Frankly, I have always been a touch dubious about Ceneral Speech courses, such as those Paul mentions. Unless their point is, as with Dale Carnegie courses, to somehow spruce up delivery, or elocution, I see little point to them. Because, in the end, what good speaking consists in is understanding what you are speaking about - and Ceneral Speech courses cannot deliver this understanding. If Paul is suggesting that "general reasoning" courses make about as much sense as "general speech" courses, then I agree with him.

One final point. If thinking is always about something (e.g. some $X$ ), as 1 have suggested, then "critical thinking" per se is even more so, that is, more transitive. This is because critical thinking as such, is a kind of higherorder thinking about things (e.g. problems, solutions, and questions), and is, therefore, parasitic upon the original thing being thought about. A person might, for example, be thinking about something but might yet not be in a position to think critically about that something. This is because critical thinking, as such, requires more than a minimal amount of understanding of that which is thought about. It is this consideration which leads me to hold that "critical thinking" is specific to the kind of thing being thought about. And insofar as there are logically different kinds of things to think about (e.g. problems and questions), it follows that there are logically different kinds of critical thinking. Hence, I oppose general critical thinking courses, which are supposed to be about everything in general and nothing in particular. I see nothing particularly "bizarre" in this rejection-quite the contrary.

The second argument Paul marshals to support his charge of "atomism" centres around the "multi-categorical" character of most real problems. Paul argues that because $I$ hold rationality and critical thinking to be domain-or subject-specific (i.e. atomistic, or specialists, he calls it), 1, therefore, cannot handle most real, or "everyday" problems, because such problems do not lie clearly in one domain or another, but in several at once. They are "multi-categorical." This is what I take to be the general thrust of his argument.

Let me say straightaway that I agree that most (but not all) real problems do lie in several domains at once, and are multi-textured and multi-categorical. I have no problems with this observation, and have been at pains to 
point it out myself in numerous places. What has gone wrong in Paul's argument is, again, to misinterpret my view regarding how domain-specific knowledge and understanding function to help us solve real problems. One of the reasons that I have been such a strong advocate of liberal education to develop critical thinking capacity is because 1 believe such an education helps to anticipate the multi-categorical nature of most problems. A person needs several different kinds of knowledge and understanding to appreciate the different dimensions of most real problems. Real problems are indeed multifaceted and complex, and this is why no single set of skills, or clump of specific knowledge, can resolve them adequately.

When I talk about "domains of knowledge," it should be understood that 1 have something quite broad in mind. They are very close to Paul Hirst's notion of a "form of knowledge," or "form of rational discourse." (All of these notions originate in what Wittgenstein refers to as different "language games.") A liberal education enables a person to understand the different characteristics, procedures, "rules," and concepts which make up these broad "domains of rational discourse" : and these are what one brings to bear on everyday problems. Metaphorically, we might think of a rational agent coping with the world in a similar way as the marine crab (i.e. the crustacean) copes with its aquatic environment. A crab is a single organism, yet it is composed of several different kinds of limbs, each designed to do a specific kind of job. It has pincers for holding things, antenas for navigating and checking-things-out, as well as several different pairs of legs, some of which are for balance, some for digging, and others for propulsion. Each specific kind of limb plays its role in enabling the crab to cope with its world. And more often than not (though not always) it uses several of its different kinds of limbs to cope with a single problem: each limb does its specific bit. Similarly, rational human beings possess several logically distinct kinds of knowledge/ understanding. And each kind (or kinds) of knowledge plays its particular role in solving particular problems. Should one of these domains be missing in a person (like a crab limb, ) or even under-developed, we might consider the person seriously deficient-as a crab without pincers, say. Liberal education tries to develop overall rationality by teaching people to understand, and to use, the different forms of rational discourse (e.g. math, science, morality, art, philosophy, etc.). Each form of knowledge provides a different kind of understanding and, therefore, can do different kinds of jobs (like different crab limbs). None of this suggests, however, that problems fall neatly into one domain of understanding or another, nor that only one domain is required to solve any problem.

What determines which domains of understanding will be required for any given problem depends, of course, on what the problem is, and what precisely you want answered. Consider, for a moment, Paul's putative counter example to my thesis. He says:

Most of what we say and think, to put it another way, is not only open-but multi-textured as well. For example, in what logical domain does the (technical?) concept of alcoholism solely belong: disease, addiction, crime, moral failing, cultural pattern, life-style choice, defect of socialization, self- comforting behaviour, psychological escape, personal weakness,...? How many points of view can be used to illuminate it? Then, are each of them in one or many categories?

My answer to all of these questions is that it depends on what, precisely, 
you want to know or say about alcoholism. If one is interested in how widespread it is, or in which age-group, then it is a sociological question. If one wants to know if it is right or wrong, then it is a moral question. If one wants to know why people become alcoholics, then it is a psychological question. If one wants to know whether it is sinful, then I suppose this is a religious question. Many different kinds of things can be said and done with respect to alcoholism. It is simply one of those many things which do not belong to one and only one category. But as soon as one raises a specific kind of question about it, then a specific kind of answer will be appropriate; and one will then have to draw upon the specific knowledge and understanding they have about that kind of question. Moreover, one kind of knowledge about things (like alcoholism) can often affect other beliefs one has about it as well. For example, if you believed alcoholism to be a disease, then you might not view it as a sin. But all of these cross-influences, and multi-texturedness, does not gainsay the existence of categories through which we perceive, talk and think about things. Indeed, rational belief and action is often predicated on seeing things from these different perspectives; and people are not born with these different perspectives; they must learn them. Again, this is what a liberal education attempts to provide.

While some concepts, then, fall into several categories, there are also important concepts which are specific (or unique) to certain domains. For example, the notion of "moral obligation" belongs to ethics, just as "electro-magnatism" belongs to physics, and "chiaroscuro" to art, "deity" to religion, "essence" and "ontology" to philosophy, and "differential equation" to mathematics, etc. Thus, some problems and questions we might have are peculiar to specific domains and, therefore, require knowledge of these domains in order to say anything intelligent about them. Of course, one can have varying degrees of such knowledge. Thus one might be able to say and do some things within the domain but not others. One's abilities here are a function of one's knowledge in the domain.[1]

Moreover, I want to stress two further points about this domain-specific knowledge. First, it is not simply esoteric or useless knowledge designed to serve the interests of academic specialists, but rather, education, as such, consists in introducing people to the fundamentals of this knowledge in order to increase their rational capacities. Second, very many (if not most) so-called "everyday problems" need to employ domain-specific knowledge of this sort, if the discussion is to move beyond a superficial level. Indeed, this is why the more persistent "everyday problems" such as disarmament, pollution, pornography, etc. are not amenable to quick solutions. They require several different kinds of specific knowledge and judgment, and sometimes in considerable amount. A broad liberal education is simply the best that we can do to bring average citizens up to the task of making rational judgments about such problems. And even this, per force, will be incomplete and fallible. But it is likely to be our best bet. Considerations such as these are what prompted my comment that "in this age of increased special knowledge, there are few Renaissance men." It was not meant to suggest that all problems fall neatly into one specialist's domain or another, as Paul interprets it.

Two brief (and final) points about Paul's charge of "atomism" and knowledge domains. First, there have been 13 published reviews of my book to date, and Richard Paul's is the first to construe my view as specialistic (or atomistic). It has been quite clear 
to most readers that $I$ call for a broad liberal education, and that this is not "atomistic." I think, therefore, that his misinterpretation of my position is more his own doing than it is mine. Second, Paul states in several places that a person's "world view," or knowledge "uberhaupt," plays a crucial role in their critical thinking capacities. I could not agree more. However, if Paul would take the time to examine seriously the ingredients of a person's "world view," I think he would find it composed of certain kinds of beliefs and knowledge structures (i.e. cognitive schemata) which is precisely what liberal education attempts to influence and enlighten. Thus, there is actually more agreement here than Paul seems comfortable to admit. I just don't think his continued use of the phrase "world view" adds anything different to what we are already familiar with-but I have no objection to the phrase.

Enough about the major philosophical differences between Paul's view and my own. There remains one niggling point which I will briefly comment upon here only because Paul devotes so much space to it, and I might seem remiss if I omitted it.

In the middle of Paul's review he charges me with presenting critiques of the work of Scriven, D'Angelo, Ennis, and Johnson and Blair which are "unfair," "unsympathetic," and "at times highly misleading." Clearly, I cannot go over all of this ground again without writing another book. But a few comments, at least, are in order. First, if I have been "unfair" to any of these writers, I hereby apologize for it. They may rest assured that any unfairness was unintentional. One does one's best. I might say, however, that I have had lengthy contact with both Scriven and $D^{\prime}$ Angelo since the book was published, and neither of them ever suggested that my treatment of them was unfair. Indeed, despite re- maining differences over more technical matters, they have both thanked me for much of my critique. Johnson and Blair strongly disagree with my views about informal logic, but they have never written (nor said) that I was unfair, nor seriously misrepresented their views.

Ennis, apparently, does think that I have been unfair to his view. But disagreement, which there is, does not amount to unfairness nor "misleading representation," as Paul charges. Ennis' so-called "range definition" remains an attempt at definition, nonetheless; and one which I find deficient for all the reasons which I provided. Its core ingredient consists in a list of "general reasoning skills" which I reject. Moreover, Ennis still clings to the idea that "general reasoning skills" should be taught in order to improve critical thinking. He reiterates this point again and again in several recent publications. I think he is wrong about this for all the reasons I have given in the book, here, and elsewhere. This disagreement is not "misrepresentation," but a bona fide difference of opinion.

With respect to Ennis leaving out any treatment of value judgments, and making that clear to his reader, I specifically discuss this point on p. 54 of my book. Indeed, I explicitly quote Ennis' own words explaining why he left it out; moreover, it does not appear in a footnote somewhere, but in the middle of the text itself. So there is no attempt at "misrepresentation" here. I then go on to point out that it is a serious omission because his "pragmatic dimension" of critical thinking necessarily requires making value judgments. I still think this is correct. But even if Paul (or perhaps Ennis) disagrees with this observation, it is not misrepresentation.

To conclude, I want to address two relatively minor, but interesting, comments of Paul's. The first comment ap- 
pears in Paul's final, but lengthy, footnote. Here, Paul questions and criticizes the appropriateness of a book on critical thinking devoting an entire chapter to Edward de Bono's work on thinking. Paul makes several points: (1) de Bono does not explicitly treat critical thinking as most of us understand that phrase (rather, he treats "problem solving" and "creativity" more than anything else); (2) de Bono is not in the same theoretical league as Scriven, Ennis, et al.; and (3) perhaps de Bono was only included for his "celebrity." I must remind Richard Paul (and possibly the reader) that I consider myself a philosopher of education and I write from that perspective. Indeed, the title of my monograph is Critical Thinking and Education. Thus, whatever Richard Paul's particular theoretical pretences, it just happens to be the case that de Bono's thinking programs are widely used in schools throughout the world and, therefore, have direct educational relevance. Moreover, these programs are very commonly used in many schools as bona fide critical thinking programs. Thus, first, if I had not treated deBono at some length, educators the major audience) would have found the omission indeed very strange; and, second, my purpose was to expose the inherent weaknesses in de Bono's programs for educators and philosophers alike. I still believe this needed to be done for educators, and this is the kind of contribution that philosophers of education often make. Interestingly, I have received several letters from philosophers of education in Great Britain, where de Bono's programs are widely used, who were greatly appreciated of that chapter in particular. (Antony Flew also has commented to this effect in the Times Educational Supplement, 29, 1, 1982.) These, then, were the reasons for treating de Bono's work at some length. And finally it remains a mystery to me why Richard Paul, given his reservation about de Bono's status, invited him to speak at his Sonoma conference on thinking, though I am happy that he did so.

The second minor point to be treated here relates, similarly, to Paul's apparent ignorance about developments in the field of philosophy of education proper. Paul quotes a statement of mine about education and schooling that he apparently finds so cockeyed that it doesn't even warrant a counterargument by him. He just confidently states that his reader will not be "comfortable" with it either. He quotes my saying "there is nothing in the logic of 'education' that requires that schools should engage in education" and "nothing contradictory in saying 'This is a fine school, and 1 recommend it to others, even though it does not engage in education.' "To Paul, such a locution sounds patently absurd; to me, it is almost trivially true. This conflict of opinion is a dramatic example of something which Harvey Siegel has drawn to people's attention in several recent papers, namely: that it "is high time that the Informal Logic Movement confront the philosophy of education." (See his "Educating Reason: Critical Thinking, Informal Logic and the Philosophy of Education" in the APA Newsletter on Teaching Philosophy, Special Issue on Informal Logic and Critical Thinking, SpringSummer, 1985, p. 10.) It is quite clear to Siegel, and myself, that the ILM continues to proceed along its high-profile path without the slightest knowledge of the more serious literature in the philosophy of education. To anyone who had read R.S. Peters or Paul Hirst, or Robert Dearden, or a number of contemporary American philosophers of education, they would immediately understand that 'schooling' and 'education' are conceptually different things, and neither one entails the other. There are ballet schools, barber schools, flight schools, and numerous 
other kinds of schools whose purpose is not education in the normal (or traditional) sense, but rather training of some kind. A highly trained barber may or may not be educated. In short, some schools are avowedly not in the business of producing "educated people." They are teaching something else, e.g., different job skills, etc. The purpose of schools in many Third-World countries is to teach improved agricultural skills, road-building, hygiene, and the like, perhaps so that they might eventually have the luxury of educating their populations in the more traditional sense. What schools are for is a social decision which varies from place to place, and sometimes from school to school. Thus, there is nothing particularly strange, nor contradictory, in my saying "there is nothing in the logic of 'education' that requires that schools should engage in 'education'." Much goes on in schools which has nothing to do with 'education,' as such; and conversely, much 'education' (e.g. self-education) does not take place in schools. Philosophers of education know this.
1. An extensive review of recent psychological investigations into reasoning and reasoning skills has been published by Robert Claser (University of Pittsburgh) in The American Psychologist, February 1984, entitled "Education and Thinking: The Role of Knowledge." This paper points out that most of the responsible research in this field strongly supports the view that domain-specific knowledge is the major determinant of reasoning skill. Even Artificial Intelligence (Al) research is making stronger progress since it has turned away from a "general strategies approach" and toward a "knowledgebased approach." (See also Minsky, M. and Papert, S. (1974) Artificial Intelligence. Eugene OR: Oregon State System of Higher Education.) Much rhetoric to the contrary, defenders of generalized reasoning skills (e.g. the ILM) are defending a rear-guard action and not a new break-through.

Dr. John McPeck, Faculty of Education, Althouse College, University of Western Ontario, London, Ontario N6A 3K7 